\title{
PROTECTIVE ROLE OF CRUDE EXTRACT OF AMORPHOPHALLUS CAMPANULATUS AGAINST ETHANOL-INDUCED OXIDATIVE RENAL DAMAGE
}

\author{
SUBHASHREE BASU ${ }^{1,2}$, MOUMITA DAS ${ }^{1}$, ANURUPA SEN ${ }^{3}$, GOURIPROSAD DATTA $^{1 *}$ \\ ${ }^{1}$ Department of Physiology, Rammohan College, 85A, Raja Rammohan Sarani, Kolkata, West Bengal, India. ${ }^{2}$ Department of Physiology, \\ Tamralipta Mahavidyalaya, Purba Medinipur, West Bengal, India. ${ }^{3}$ Department of Physiology, City College. Email: dattagp@yahoo.co.in
}

Received: 19 April 2017, Revised and Accepted: 12 October 2017

\section{ABSTRACT}

Objective: The current study investigates the nephroprotective effect of Amorphophallus campanulatus against chronic alcohol-induced oxidative stress and tissue damage.

Methods: The rats were simultaneously supplemented with ethanolic extract of $A$. campanulatus along with ethanol (40\% w/v) 2 g/kg body weight/day for 30 days to evaluate the nephroprotective effect against alcohol toxicity. Renal antioxidant enzymes, serum urea, creatinine, and proinflammatory cytokines were assayed biochemically. Histomorphological and histochemical alterations were detected by Hematoxylin and Eosin, periodic acid Schiff, and Feulgen and Picrosirius stain, respectively. The degree of apoptotic cell death was examined by terminal deoxynucleotidyl transferase dUTP nick end labeling (TUNEL) assay technique.

Results: Serum urea, creatinine, pro-inflammatory cytokines, tissue TBARS, and activity of glutathione metabolizing enzymes were significantly $(\mathrm{p}<0.01)$ elevated, whereas cytosolic and mitochondrial superoxide dismutase, catalase, and levels of reduced glutathione were significantly ( $<0.001)$ decreased in the EtOH group compared to control. However, ethanolic extract of $A$. campanulatus (ACE) supplementation to the EtOH rats reversed these effects to normal levels. Furthermore, degenerative changes in renal cells with alcohol treatment were minimized to nearness in architecture by ACE supplementation. Glycogen and deoxyribonucleic acid depletion, excess fibrosis due to collagen deposition, and increased apoptotic cell number were also restricted by ACE supplementation, with the higher dose being more promising.

Conclusion: Thus ethanol-induced nephrotoxicity was attenuated by ACE treatment by the antioxidative and antiapoptotic property of the extract. Such effects of the extract may be due to the probable presence of different bioactive components in the tuber. Hence, it can be used as a regular nutrient or therapeutic agent to protect the renal cells.

Keywords: Apoptosis, Fibrosis, Nephrotoxicity, Oxidative stress, Pro-inflammatory cytokines, TUNEL.

(C) 2018 The Authors. Published by Innovare Academic Sciences Pvt Ltd. This is an open access article under the CC BY license (http://creativecommons. org/licenses/by/4. 0/) DOI: http://dx.doi.org/10.22159/ajpcr.2018.v11i1.19286

\section{INTRODUCTION}

Consumption of alcoholic beverages is considered as a usual habit in most societies around the world. Alcoholism is a serious human health ailment that can disturb the important defense systems in the body, including kidney tissue. The liver is the primary organ responsible for the oxidation of ingested alcohol, but other tissues, including the kidney, may contribute to alcohol metabolism as well [1]. Regular alcohol consumption raises the blood pressure, which per se is a risk factor for renal damage [2]. Besides, excess alcohol intake increases free radical or reactive oxygen species (ROS) production and causes oxidative stress by compromising the antioxidant defense system, production of the reactive product acetaldehyde, damage to mitochondria, and altered cytokine production [3-5]. ROS-induced altered antioxidant system causes continued damage to the vital biomolecules, and this condition ultimately gives way to impaired kidney function [6]

In the recent time, many natural products are being used to protect the tissues from various drugs or chemical-induced toxicities. The use of plants as food and medicinal remedies since ancient times is partially attributed to the biological efficacy of secondary metabolites that possess antioxidant activities such as phenolic compounds, Vitamins C and E, and carotenoids [7].

Currently, research interest has been focused on the role of antioxidants as well as antioxidant enzymes, in the treatment and prevention of the diseases mentioned above. The most commonly used antioxidants at present are vitamins, butylated hydroxyanisole, butylated hydroxytoluene, propyl gallate, and tert-butylhydroquinone. However, they are suspected of being responsible for liver damage and acting as carcinogens in laboratory animals. Therefore, the development and utilization of more effective antioxidants of natural origin are desirable [8].

In Southeast Asian countries, besides vegetables, tuber crops also contribute to a major part of the staple diet. They are of immense importance because of their high calorific value. One such popular tuberous crop in India, especially the south and eastern region, is Amorphophallus campanulatus commonly known as "suran" in Sanskrit and elephant yam in English. A. campanulatus has its mention in Ayurveda.

Recently, from our laboratory, we reported the in vitro antioxidant potential of a hydroethanolic extract of A campanulatus against DPPH, hydroxyl, and superoxide radical [9]. Besides, we have also studied the various bioactive components in the extract by GC-MS analysis and found that the extract had several bioactive components with antioxidant potency along with good source of components such as hexadecanoic acid and its methyl and ethyl esters, heptadecanoic acid, linoleic acid and its ester, oleic acid, stigmasterol, 1, 3, 5, benzenetriol, 4H-pyran-4-one, 2, 3-dihydro-3, 5 -dihydroxy-6-methyl-, squalene, and Vitamin E [10]. None the less, hepatoprotective activity of the hydroethanolic extract against ethanol-induced oxidative stress in albino rats has also revealed an upregulation of in vivo antioxidant defense system and simultaneous attenuation in the level of tissue lipid 
peroxidation products [11]. However, treatment of ethanol-induced nephrotoxicity by antioxidant formulations has not received a wide recognition. Inspite of the tremendous advances made in allopathic medicine, no effective reno-protective medicine is yet available. Hence, in the present study, we made an attempt to explore the nephroprotective effect of hydroethanolic extract of A. campanulatus against ethanol-induced oxidative stress and tissue damage. The protective effects of the extract have been monitored by assaying the antioxidant enzymes, TBARS, and pro-inflammatory cytokine levels on the one hand, along with histological and histochemical analyses on the other, in ethanol-treated rats.

\section{METHODS}

\section{Chemicals}

Activated charcoal (Merck, India), bovine serum albumin (Merck, India), basic fuchsin (Merck, India), copper sulfate (Merck, India), di-sodium hydrogen phosphate (Merck, India), eosin (Merck, India), direct red (Sigma St. Louis, MO), ethylenediaminetetraacetic acid (Merck, India), Folin-Ciocalteu (Merck, India), formaldehyde (Merck, India), glutathione reduced (Hi-Media, India), glutathione oxidized (HiMedia, India), glucose-6-phosphate (Hi-Media, India), hematoxyline (Merck, India), hydrochloric acid (Merck, India), hydrogen peroxide (Merck, India), kits for urea and creatinine (Span Diagnostics, India), nicotinamide adenine dinucleotide phosphate (Hi-Media, India), nicotinamide adenine dinucleotide hydrogen phosphate (Hi-media, India), potassium di-hydrogen phosphate (Merck, India), parrafin wax (Merck, India), periodic acid (Merck, India), pyrogallol (HiMedia, India), picric acid (Merck, India), Rat interleukin (IL)-6 and tumor necrosis factor-alpha (TNF- $\alpha$ ) (Ray Biotech, USA), sodium azide (Hi-Media, India), sodium-potassium tartrate (Merck, India), sodium hydroxide (Merck, India), sodium chloride (Merck, India), sodium dihydrogen phosphate (Merck, India), sodium hydrogen carbonate (Merck, India), sodium carbonate (Merck, India), sulfuric acid (Merck, India), thiobarbituric acid (Hi-Media, India), tris buffer (Merck, India), and xylene (Merck, India) were used.

\section{Plant material}

Fresh tubers of A. campanulatus (AC) were purchased from the farmers of Santragachhi village of Howrah district, West Bengal, India, from May to October. The plant and its parts were botanically authenticated by the Botanical Survey of India (BSI), Howrah, West Bengal, India. A voucher specimen of A. campanulatus (Roxb.) Blume ex Decne was deposited at the institute herbarium, Department of Physiology, Rammohan College under the University of Calcutta bearing the number RMC/PHY/SB/03/14.

\section{Extract preparation}

Raw fresh tubers after procurement were cut into thin slices and washed under running tap water to remove any impurity and mud. After proper cleaning, the wet materials were soaked in blotting paper and then dried in hot air oven at $50^{\circ} \mathrm{C}$ until materials became crispy in texture. This dried material was grinded into coarse powder form and stored at $-4^{\circ} \mathrm{C}$ in airtight Tarson jars until further use.

For the preparation of the hydroethanolic extract, $20 \mathrm{~g}$ of the powdered dried sample was taken in the thimble of Soxhlet and extracted with $250 \mathrm{ml}$ of ethanol $(70 \%)$ in the round bottomed flask continuously for a week. The extract was then filtered through muslin cloth, centrifuged, and the collected filtrate was first concentrated followed by evaporation to dryness using rotary evaporator (B.C. Chatterjee \& Co., Kolkata, West Bengal, India) at $50-55^{\circ} \mathrm{C}$. The percentage yield of the extract is $12.5 \pm 1.38 \%$ per $20 \mathrm{~g}$ of dried sample $(\mathrm{w} / \mathrm{w})$. The dried sample, hydroethanolic extract of $A$. campanulatus (ACE) was collected and stored in airtight plastic vials at $-4^{\circ} \mathrm{C}$ for future use.

\section{Animal care and treatment}

Wistar strain male albino rats weighing $170-200$ g $( \pm 7.54)$ body weight were procured from M/s Ghosh Enterprise, (Kolkata, India). The rats were housed in autoclavable polypropylene cages and maintained in air-conditioned temperature-controlled room $\left(25^{\circ} \pm 2^{\circ} \mathrm{C}\right)$ with 12:12 h L: D photoperiod. Rats were given standard pellet diet (Lipton, Rat Feed, Ltd., Pune, India) containing 18\% protein, 10\% fat, and $70 \%$ carbohydrate along with essential vitamins and minerals in adequate amount. Water was provided ad libitum throughout the experimental period. All experiments were in accordance with the guidelines of the Committee for the Purpose of Control and Supervision of Experiments on Animal (CPCSEA), Government of India, (1795/PO/ ERe/S14CPCSEA).

Acute toxicity study of ethanolic extract of $A$. campanulatus tuber and determination of minimum lethal dose $\left(\mathrm{LD}_{50}\right)$

Acute oral toxicity study was conducted according to the Guidelines for Testing of Chemicals adopted by the Organization for Economic Cooperation and Development [12]. The median $\mathrm{LD}_{50}$ of the plant extract was determined by method of Lorke [13] using twelve rats weighing between 150 and $190 \mathrm{~g}$. In the first phase, four rats were divided into two groups of two rats each and were treated with the hydroethanolic tuber extract of the plant at dosages of 1600 and $2000 \mathrm{mg} / \mathrm{kg}$ body weight intraperitoneally. They were observed for $24 \mathrm{~h}$ for signs of toxicity. In the second phase, eight rats were again divided into four groups of two rats each and were also treated with the hydroethanolic extract of A. campanulatus at dosages of 3000, 3500, 4000, 4500, 5000, 5500 , and $6000 \mathrm{mg} / \mathrm{kg}$ body weight intraperitoneally. The median $\mathrm{LD}_{50}$ was calculated using the second phase.

\section{Experimental design}

Rats were divided into six groups with six rats in each group, and those were treated as follows for thirty consecutive days:

- Group I: Control (Cont) fed on standard diet and water and received $0.9 \%$ normal saline, $0.5 \mathrm{ml} /$ day intraperitonially.

- Group II: Negative control (EtOH) treated with $40 \%$ ethanol (v/v) $(2 \mathrm{~g} / \mathrm{kg}$ body weight/day), intraperitonially along with standard diet and water.

- Group III: ACE (250 mg/kg body weight/day, i.p.)+40\% ethanol (v/v) treated group along with standard diet and water (EtOH+ACE250).

- Group IV: ACE (500 mg/kg body weight/day, i.p.)+ 40\% ethanol (v/v) treated group along with standard diet and water (EtOH+ACE500).

- Group V: ACE $(250 \mathrm{mg} / \mathrm{kg}$ body weight/day, i.p.) along with standard diet and water (ACE250).

- Group VI: ACE (500 mg/kg body weight/day, i.p.) along with standard diet and water (ACE500).

The dose of ethanol was taken as $40 \%$ ethanol $(\mathrm{v} / \mathrm{v})$ prepared from absolute ethanol (Merck, India), as the standardized dose, obtained from the previous studies on hepatotoxicity performed in our laboratory [11].

In the experiment designed, equal volume of the saline, ethanol, and the extract were administered through intraperitoneal route as absorption of these takes place immediately in exactly the same amount as that applied, avoiding fast pass metabolism [14]. It is also important to note that forced alcohol administration can initiate stress response, manifested by an increased release of glucocorticoids, which can be immunosuppressive [15,16]. Besides, intragastric administration through oral gavage may cause more stress than intraperitoneal route if not performed properly.

\section{Collection of sample}

After 30 days of continuous treatment, the animals were kept fasted overnight without any treatment. The day following, the animals were sacrificed after being anesthetized with an intraperitoneal injection of a combination of $100 \mathrm{mg} / \mathrm{kg}$ of ketamine and $10 \mathrm{mg} / \mathrm{kg}$ xylazine [17]. Blood samples were collected by cardiac puncture. The collected blood was allowed to stand for some times to separate out the serum. Kidney tissues were excised, trimmed of connective tissues, rinsed with ice-cold saline to eliminate blood contamination, dried by blotting with filter paper, and weighed to obtain the organ weight. Part of the tissue was used for homogenate preparation, and the other part was transferred to fixative for the preparation of histological sections. 


\section{Biochemical assays}

Serum urea level [18] and creatinine concentration [19] were determined using commercially available kit reagents manufactured by Span Diagnostics Ltd, India. Absorbances at different wavelengths were measured using ultraviolet (UV)-visible Single-Beam Spectrophotometer (Systronics 118). Blood urea nitrogen (BUN) was calculated using the following equation as mentioned in the manufacturer's kit:

BUN $(\mathrm{mg} / 100 \mathrm{ml})=($ Concentration of serum urea in $\mathrm{mg} / 100 \mathrm{ml}) \times 0.467$

\section{Preparation of post-mitochondrial supernatant (PMS)}

A $20 \% \mathrm{w} / \mathrm{v}$ kidney tissue homogenate was prepared in ice-cold phosphate buffer saline containing 1 mM EDTA (pH 7.4), using power drive Teflon homogenizer (REMI, Vasai, India). The homogenate was then centrifuged at $10,000 \mathrm{rpm}$ for $30 \mathrm{~min}$, at $4^{\circ} \mathrm{C}$. The supernatant thus obtained called PMS was used further for biochemical assay of tissue oxidative stress markers [20].

\section{Preparation of mitochondrial fraction}

For mitochondrial preparation, the kidney homogenate was first centrifuged at $2000 \mathrm{rpm}$ for $5 \mathrm{~min}$. The supernatant was collected and centrifuged again at $10000 \mathrm{rpm}$ for $20 \mathrm{~min}$. The supernatant thus formed was discarded, and the pellet was suspended in Tris-HCl buffer (pH 7.4).

\section{Assessment of oxidative stress markers}

Renal superoxide dismutase (SOD) activity, both cytosolic and mitochondrial, was assayed from the tissue homogenates by the method of Marklund and Marklund [21] at $420 \mathrm{~nm}$ for $5 \mathrm{~min}$ on a Systronics-118 UV-visible spectrophotometer. Activity was expressed as the amount of enzyme that inhibits the autoxidation of pyrogallol by $50 \%$, which is equal to $1 \mathrm{U}$ of enzyme activity.

Catalase (CAT) activity was determined at room temperature by the modified version of Aebi [22], and the absorbance of the sample was measured at $240 \mathrm{~nm}$ for $1 \mathrm{~min}$ in an UV-spectrophotometer. Change in the rate of absorbance was converted to $\mu$ moles of $\mathrm{H}_{2} \mathrm{O}_{2}$ consumed $/ \mathrm{min} /$ mg protein.

The concentration of reduced glutathione (GSH) in kidney homogenates was measured as described by the method of Ellman [23]. The intensity of the yellow color formed by adduct formation of Ellman's Reagent (DTNB) with sulfydryl group of reduced glutathione was measured spectrophotometrically at $412 \mathrm{~nm}$.

The extent of lipid peroxidation was estimated as the concentration of thiobarbituric acid reactive product MDA using TBA/TCA [24]. The optical density of the pink chromogen formed due to adduct formation between TBA and lipid peroxidation products were measured spectrophotometrically at $532 \mathrm{~nm}$.

Glutathione peroxidase (GPx) was estimated by the method of Rotruck [25], using the principle of the amount of glutathione utilized. The enzyme activity is an indirect measure of glutathione utilized and expressed as $\mu$ moles of GSH consumed $/ \mathrm{min} / \mathrm{mg}$ protein. Simultaneous blank/control was maintained without the tissue homogenate (i.e., the absence of enzyme source) to obtain the actual amount of glutathione content. Glutathione content was measured spectrophotometrically at $412 \mathrm{~nm}$.

Glutathione reductase was estimated by the method of Racker based on the amount of NADPH utilized to convert GSSG to GSH spectrophotometrically at $340 \mathrm{~nm}$. The enzyme activity was calculated using molar extinction coefficient and expressed as $\mu$ moles of NADPH utilized/min/mg protein [26].

Glutathione-S-transferase (GST) was measured spectrophotometrically at $340 \mathrm{~nm}$ by estimating the CDNB-GSH conjugate formation [27].
The values were calculated using molar extinction coefficient, and the activity was expressed as $\mu$ moles of CDNB-GSH conjugate formed/ $\mathrm{min} / \mathrm{mg}$ protein.

Glucose-6-phosphate dehydrogenase (G-6-P-D) was estimated by the method of Lee [28] using NADP and glucose-6-phosphate as substrate. Consumption of substrate with time was reflected in change in absorbance which was recorded at $340 \mathrm{~nm}$ for $3 \mathrm{~min}$. The activity was expressed as $\mathrm{U} / \mathrm{mg}$ protein where 0.01 change in $\mathrm{OD} / \mathrm{min}$ corresponded to $1 \mathrm{U}$.

All enzyme activities were expressed per mg protein, and the tissue protein was estimated according to the method of Lowry [29] using bovine serum albumin as a standard.

\section{Assessment of inflammatory markers}

The involvement of inflammation in ethanol-induced hepatic damage was assessed by measuring the levels of TNF- $\alpha$ and IL- 6 in the serum of the different animal groups. Both IL- 6 and TNF- $\alpha$ levels were assessed using RayBio ${ }^{\circledast}$ Rat IL- 6 and RayBio ${ }^{\circledR}$ Rat TNF- $\alpha$ ELISA Kits (RayBiotech, Inc., Norcross, GA, USA), respectively. The steps were carried out according to the manufacturer's instructions. The absorbances at specified wavelengths were carried out using ELISA microplate reader (Alere, AM 2100).

\section{Histopathology}

Kidney specimens from all experimental groups were fixed in $10 \%$ formol saline for $24 \mathrm{~h}$. Washing was done by tap water, and then, serial dilutions of alcohol (ethanol) were used for dehydration. Specimens were cleared in xylene and embedded in paraffin at $56^{\circ} \mathrm{C}$ in a hot air oven for $24 \mathrm{~h}$. Sections were embedded in paraffin and sliced into $4 \mu \mathrm{m}$ thick sections by a rotary microtome. The tissue sections were collected on glass slides, deparaffinized, and stained with hematoxylin and eosin (H\&E) [30]. The tissue sections were viewed under microscope (Magnus, MLXi), and images were captured using a digital camera Olympus BX51 (Olympus Corporation, Tokyo, Japan) attached to it

\section{Histochemistry}

Periodic acid Schiff (PAS) stain and Schiff's Feulgen reaction were also performed on renal tissue sections to determine changes in glycogen and deoxyribonucleic acid (DNA) content, respectively [30].

Renal tissue sections were stained with direct red also known as Picrosirius stain (Sigma Aldrich, Germany) for determination of collagen deposition and assessment of tissue fibrosis [31]. The sections were viewed under light microscope as well as laser scanning confocal microscope (Leica TCS, SP2, Germany), and the stacked images through multiple slices were captured.

The digitized images of PAS stain, Feulgen stain, and Picrosirius stain were then analyzed using image analysis system (Image J, NIH Software, Bethesda, MI). The total glycogen, DNA, and collagen area fraction of each image were measured and expressed as the \% glycogen, DNA, and collagen volume, respectively.

\section{Assessment of apoptotic cells by TUNEL assay}

Terminal deoxynucleotidyl transferase-mediated dUTP nick end labeling (TUNEL) (Trevigen, Gaithesberg, Maryland) assay was also performed on paraffin-embedded sections to assess apoptotic cells using Apo-BrdU-IHC in situ DNA fragmentation assay kit. For laser confocal microscopy, fluorescein isothiocyanate labelled dUTP solution was used. Digitized images under light microscope and laser scanning confocal microscope (Leica TCS, SP2, Germany) were taken. TUNEL fragmented DNA $/ \mathrm{mm}^{2}$ is calculated using image analysis system (Image J, NIH Software, Bethesda, MI).

\section{Statistical analysis}

Statistical analysis was performed using SPSS v.20.0. Results were articulated as mean \pm standard deviation (SD). Multiple comparisons 
were done using one-way ANOVA followed by Tukey-Kramer post hoc analysis after ascertaining the homogeneity of variances between the treatment groups.

\section{RESULTS}

\section{Acute toxicity study}

While animals that received very high dosage died, other signs of toxicity were noticed $2-4 \mathrm{~h}$ after extract administration. There were decrease in locomotion, writhing, and sensitivity to touch. The median $\mathrm{LD}_{50}$ was calculated as follows:

$\mathrm{LD}_{50}=\sqrt{\mathrm{D} 0} \times \mathrm{D} 100$

Where $\mathrm{D}_{0}=$ Dosage of $0 \%$ mortality

$\mathrm{D}_{100}=$ Dosage of $100 \%$ mortality

Thus, $\mathrm{LD}_{50}=\sqrt{5000 \times 6000}=\sqrt{30,000,000 \mathrm{LD} 50}=5477.22 \mathrm{mg} / \mathrm{kg}$

The extract was found to be safe up to $5000 \mathrm{mg} / \mathrm{kg}$ body weight with no signs of toxicity or behavioral alteration in the animals. Therefore, in this present study, $1 / 20^{\text {th }}$ and $1 / 10^{\text {th }}$ concentration of $5000 \mathrm{mg} / \mathrm{kg}$ body weight per day of the extract was chosen for determination of nephroprotective effect against ethanol toxicity.

\section{Effect on body weight and organ weight}

The final body weight of the ethanol-treated group showed significant $(\mathrm{p}<0.001)$ reduction in comparison to the control group after 30 days of the treatment period. The ethanol-treated group showed 13.73\% reduction in body weight while the control group showed $7.89 \%$ gain in body weight. Such reduction in body weight was prevented in the ethanol+ACE-treated groups at both the doses. At the first dose level, the body weight was reduced by $3.03 \%$, while at the next higher dose, the reduction was by $2.41 \%$ only, both of which are negligible when compared to the ethanol-treated group. It is worth mentioning that there was minor alteration in the body weight of only extract-treated groups after the treatment period and it is also noteworthy that the higher dose extract group showed a gain in body weight by $3.47 \%$ like that of the normal control group.

In relation to organ weight, the ethanol-treated group showed no significant $(\mathrm{p}>0.05)$ reduction in organ weight when compared to control. Table 1 represents the initial weight, final weight, and postsacrifice kidney weight/100 g body weight of the experimental group of animals.

\section{Effect on serum markers}

Table 2 shows that i.p injection of ethanol resulted in marked impairment of renal functions as reflected by significant $(\mathrm{p}<0.001)$ increase in the levels of serum urea (53.17\%), BUN (53.19\%), and creatinine $(61.01 \%)$ as compared with normal control rats. On the other hand, concomitant i.p injection of ACE at dose $250 \mathrm{mg} / \mathrm{kg}$ and $500 \mathrm{mg} / \mathrm{kg}$ body weight produced an efficient protective effect on altered renal functions. Both the doses have more or less similar potentials in improving renal

Table 1: Effect of ethanol and ACE on final body weight and organ weight in control and experimental animals

\begin{tabular}{llll}
\hline Groups & $\begin{array}{l}\text { Initial body } \\
\text { weight }(g)\end{array}$ & $\begin{array}{l}\text { Final body } \\
\text { weight }(g)\end{array}$ & $\begin{array}{l}\text { Kidney } \\
\text { weight (g) }\end{array}$ \\
\hline Cont & $175.00 \pm 5.02$ & $190.56 \pm 7.43$ & $0.588 \pm 0.068$ \\
EtOH & $186.73 \pm 6.32$ & $165.00 \pm 6.19$ & $0.443 \pm 0.054^{\text {ns }}$ \\
EtOH+ACE250 & $175.46 \pm 4.59$ & $168.00 \pm 6.08$ & $0.416 \pm 0.07^{\text {ns }}$ \\
EtOH+ACE500 & $180.45 \pm 6.75$ & $170.50 \pm 5.22$ & $0.484 \pm 0.03^{\text {ns }}$ \\
ACE250 & $172.95 \pm 5.42$ & $182.45 \pm 6.42$ & $0.457 \pm 0.05^{\text {ns }}$ \\
ACE500 & $171.46 \pm 6.09$ & $178.33 \pm 4.79$ & $0.454 \pm 0.08^{\text {ns }}$ \\
\hline
\end{tabular}

All values are expressed as mean \pm SD, of 6 animals in each group. Data are

analyzed by one-way analysis of variance followed by Tukey's-Kramer post hoc analysis. ${ }^{n s} \mathrm{p}>0.05$ versus control function markers deleteriously perturbed in ethanol-administered rats. The only extract-treated groups showed no significant change in these parameters when compared to control, indicating their non-toxic effect in the body.

Fig. 1 depicts the effect of two doses of ACE on the level of TNF- $\alpha$ and IL- 6 in control and ethanol-injected rats. Both the levels of TNF- $\alpha$ and IL-6 were elevated significantly $(\mathrm{p}<0.001)$ in the ethanol-injected group as compared with normal one. TNF- $\alpha$ was elevated by $55.28 \%$ and IL- 6 by $47.17 \%$ in the ethanol-administered group. However, administration of ACE250 and ACE500 successfully lowered the values of TNF- $\alpha$ by $34.89 \%$ and $43.34 \%$ and that of IL- 6 by $31.62 \%$ and $38.16 \%$, respectively, in a graded dose-dependent manner. Administration of ACE at two different concentrations, $1 \mathrm{~h}$ before ethanol, ameliorated the altered levels of the pro-inflammatory cytokines. The levels of these pro-inflammatory cytokines, however, showed no significant change in the only extract-treated group as compared to control.

\section{Effect on endogenous antioxidant enzymes}

Ethanol, injected i.p., developed an impaired tissue redox balance on chronic administration. In this regard, it was found that ethanol induced a remarkable elevation $(\mathrm{p}<0.001)$ in renal lipid peroxidation, assayed as malondialdehyde (MDA) level. The ethanol-treated group showed $69.35 \%$ elevated TBARS level compared to control. Besides, it is also found that ethanol caused significant $(\mathrm{p}<0.001)$ lowering of GSH content $(41.75 \%)$ and declined activities of both Cu-Zn SOD (54.54\%) and Mn-SOD $(86.31 \%)$, and CAT $(20.93 \%)$. Pre-treatment with the extract of ACE $1 \mathrm{~h}$ before ethanol administration at both lower $(250 \mathrm{mg} / \mathrm{kg}$ body weight) and higher (500 mg/kg body weight) concentration significantly $(\mathrm{p}<0.001)$ prevented elevation of TBARS content and the depletion of tissue GSH as well as exhaustion of the endogenous antioxidant enzymes. However, no significant alteration in the level and activity of the abovementioned parameters were observed among the only extract-treated and normal control rats indicating the anti pro-oxidant effect of the extract.

Unlike the traditional antioxidant enzymes, the glutathione metabolizing enzymes, which also play an important role in maintenance of internal oxidant-antioxidant milieu, change differently in the ethanol-eated group. The ethanol-treated groups showed significant $(\mathrm{p}<0.001)$ elevation in the levels of GPx (24.99\%), GST (59.88\%), GR (40.81\%), and G6PD (56.57\%) activity when compared to control. Such elevation in the activity of these enzymes was significantly $(\mathrm{p}<0.001)$ prevented when the animals were supplemented with the extract of ACE at two different concentrations. Tables 3 and 4 represent the changes in the levels of endogenous antioxidants markers in the control and experimental group of animals.

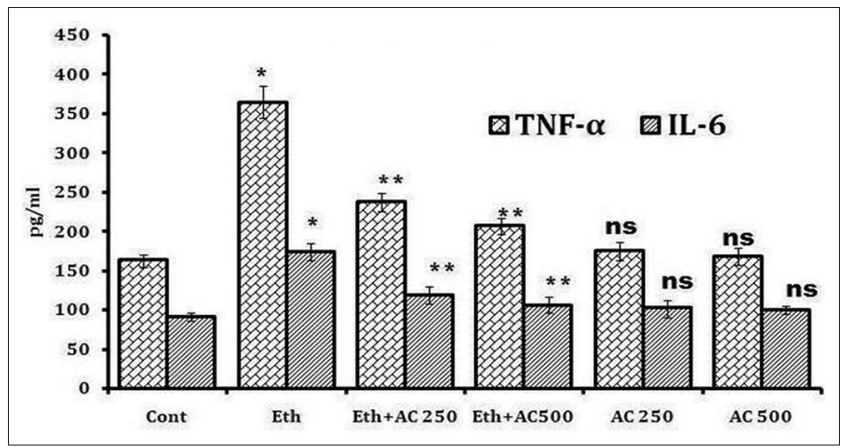

Fig. 1: Pro-inflammatory cytokine levels in experimental animal groups. All values are expressed as mean $\pm S D$, of 6 animals in each group. Data are analyzed by one-way analysis of variance followed by Tukey's-Kramer post hoc analysis. ${ }^{*} \mathbf{p}<0.001$ versus control, ${ }^{n s} \mathrm{p}>0.05$ versus control, ${ }^{* *} \mathrm{p}<0.001$ versus only ethanol 
Table 2: Effect of ethanolic extract of ACE on the levels of serum urea, creatinine, and BUN in the control and experimental rats

\begin{tabular}{llll}
\hline Groups & Urea $(\mathbf{m g} / \mathbf{d l})$ & Creatinine $(\mathbf{m g} / \mathbf{d l})$ & BUN (mg/dl) \\
\hline Cont & $25.43 \pm 3.359$ & $1.457 \pm 0.333$ & $11.871 \pm 1.57$ \\
EtOH & $54.305 \pm 6.559^{*}$ & $3.737 \pm 0.712^{*}$ & $25.36 \pm 3.06^{*}$ \\
EtOH+ACE250 & $36.64 \pm 2.53^{* *}$ & $2.156 \pm 0.366^{* *}$ & $17.20 \pm 1.10^{* *}$ \\
EtOH+ACE500 & $29.97 \pm 2.71^{* *}$ & $1.579 \pm 0.342^{* *}$ & $13.99 \pm 1.26^{* *}$ \\
ACE250 & $31.77 \pm 2.090^{\text {ns }}$ & $1.523 \pm 0.134^{\text {ns }}$ & $14.835 \pm 0.976^{\text {ns }}$ \\
ACE500 & $32.46 \pm 3.414^{\text {ns }}$ & $1.74 \pm 0.205^{\text {ns }}$ & $15.155 \pm 1.490^{\text {ns }}$ \\
\hline
\end{tabular}

All values are expressed as mean \pm SD, of 6 animals in each group. Data are analyzed by one-way analysis of variance followed by Tukey's-Kramer post hoc analysis.

${ }^{*} \mathrm{p}<0.001$ versus control, ${ }^{\mathrm{n}} \mathrm{p}>0.05$ versus control, ${ }^{* *} \mathrm{p}<0.001$ versus only ethanol. BUN: Blood urea nitrogen

Table 3: Effect of ethanolic extracts of ACE on the levels of TBARS, GSH, and activities of antioxidant enzymes (SOD and CAT) from renal tissues of control and experimental rats

\begin{tabular}{lllll}
\hline Groups & Cu-Zn SOD $(\mathbf{U} / \mathbf{m i n} / \mathbf{m g})$ & Mn-SOD $(\mathbf{U} / \mathbf{m i n} / \mathbf{m g})$ & CAT $\left(\mu \mathbf{m o l ~ H}_{2} \mathbf{O}_{2} / \mathbf{m i n} / \mathbf{m g}\right)$ & TBARS in terms of MDA $(\boldsymbol{\mu m o l} / \mathbf{1 0 0}$ g) \\
\hline Cont & $4.62 \pm 0.7$ & $5.22 \pm 0.65$ & $198.62 \pm 9.01$ & $10.41 \pm 2.1$ \\
EtOH & $2.10 \pm 0.27^{*}$ & $1.90 \pm 0.54^{*}$ & $157.03 \pm 5.16^{*}$ & $33.97 \pm 4.4^{*}$ \\
EtOH+ACE250 & $3.92 \pm 0.06^{* *}$ & $3.58 \pm 0.28^{* *}$ & $184.25 \pm 8.3^{* *}$ & $26.32 \pm 1.4^{* *}$ \\
EtOH+ACE500 & $4.36 \pm 0.62^{* *}$ & $4.51 \pm 0.82^{* *}$ & $190.03 \pm 9.8^{* *}$ & $15.47 \pm 3.97^{* *}$ \\
ACE250 & $3.55 \pm 0.05^{\text {ns }}$ & $5.02 \pm 0.55^{\text {ns }}$ & $188.18 \pm 9.9^{\text {ns }}$ & $16.03 \pm 3.9^{\text {ns }}$ \\
ACE500 & $3.85 \pm 0.1^{\text {ns }}$ & $4.98 \pm 0.19^{\text {ns }}$ & $191.35 \pm 7.9^{\text {ns }}$ & $13.79 \pm 2.9^{\text {ns }}$ \\
\hline
\end{tabular}

All values are expressed as mean \pm SD, of 6 animals in each group. Data are analyzed by one-way analysis of variance followed by Tukey's-Kramer post hoc analysis. ${ }^{*} \mathrm{p}<0.001$ versus control, ${ }^{\mathrm{n}} \mathrm{p}>0.05$ versus control, ${ }^{* *} \mathrm{p}<0.01$ versus only ethanol

Table 4: Effect of ethanolic extract of ACE on the levels of glutathione metabolizing enzymes from hepatic tissue of control and experimental rats

\begin{tabular}{|c|c|c|c|c|c|}
\hline Groups & GSH (mg/100 g) & $\begin{array}{l}\text { GPx ( } \mu \text { moles of GSH } \\
\text { consumed } / \mathrm{min} / \mathrm{mg} \text { ) }\end{array}$ & $\begin{array}{l}\text { GST ( } \mu \text { moles of CDNB-GSH } \\
\text { conjugate formed } / \mathrm{min} / \mathrm{mg} \text { ) }\end{array}$ & $\begin{array}{l}\text { GR ( } \mu \text { moles of NADPH } \\
\text { consumed } / \mathrm{min} / \mathrm{mg})\end{array}$ & G6PD (U/min $/ \mathrm{mg})$ \\
\hline Cont & $56.36 \pm 4.6$ & $56.87 \pm 9.2$ & $13.83 \pm 2.81$ & $62.02 \pm 7.36$ & $1.077 \pm 0.31$ \\
\hline EtOH & $32.83 \pm 5.9 *$ & $75.82 \pm 8.93^{*}$ & $34.48 \pm 7.93^{*}$ & $104.79 \pm 13.56^{*}$ & $2.48 \pm 0.4^{*}$ \\
\hline EtOH+ACE250 & $40.97 \pm 6.7^{* *}$ & $59.54 \pm 7.29^{* * / \mathrm{ns}}$ & $19.53 \pm 1.75^{* * / \mathrm{ns}}$ & $75.22 \pm 6.22^{* * / \mathrm{ns}}$ & $1.391 \pm 0.27^{* * / \mathrm{ns}}$ \\
\hline EtOH+ACE500 & $52.88 \pm 2.6^{* *}$ & $59.66 \pm 4.83^{* * / \mathrm{ns}}$ & $16.88 \pm 2.53^{* * / \mathrm{ns}}$ & $71.04 \pm 7.105^{* * / n s}$ & $1.11 \pm 0.22^{* * / n s}$ \\
\hline ACE250 & $50.27 \pm 6.2^{\mathrm{ns}}$ & $57.64 \pm 6.75^{\mathrm{ns}}$ & $18.29 \pm 3.13^{\mathrm{ns}}$ & $64.51 \pm 9.47^{\mathrm{ns}}$ & $1.07 \pm 0.27^{\mathrm{ns}}$ \\
\hline ACE500 & $51.67 \pm 4.98^{\mathrm{ns}}$ & $58.06 \pm 3.66^{\mathrm{ns}}$ & $19.87 \pm 4.22^{\mathrm{ns}}$ & $63.56 \pm 5.77^{\mathrm{ns}}$ & $1.11 \pm 0.13^{\mathrm{ns}}$ \\
\hline
\end{tabular}

All values are expressed as MEAN \pm SD, of 6 animals in each group. Data are analyzed by one-way analysis of variance followed by Tukey's-Kramer post hoc analysis.

${ }^{*} \mathrm{p}<0.001$ versus control, ${ }^{\mathrm{n} s} \mathrm{p}>0.05$ versus control, ${ }^{* *} \mathrm{p}<0.001$ versus only ethanol

\section{Histological alteration}

\section{Morphological changes}

Fig. 2 presents microscopic examination of renal tissue section from different experimental group shows prominent changes in renal ultrastructure among different groups. H\&E stained tissues from alcohol injected rats reveal a progressive derangement of renal cells, cellular infiltration, lipid droplet accumulation, necrotic glomeruli, and dilation of renal tubules. However, such alterations were prevented by administration of the extract of ACE at two different concentrations before ethanol, indicating its protective effect against ethanol. No such alteration in renal structure was observed in the only extract supplemented group.

\section{Glycogen content}

PAS staining for glycogen content also revealed a significant decreased storage capacity for glycogen in renal cells of ethanol injected rats. Image analysis revealed $52.94 \%$ of decreased glycogen deposition in the ethanoltreated group compared to control. The glomeruli were less positive in the ethanol-treated group as compared to control. However, the storage capacity was elevated in the extract supplemented group and remained unaltered like that of control. PAS-positive area was increased by $18.6 \%$ in ACE250 and 43.66\% in the ACE500 supplemented group. The glomeruli showed more PAS-positive area in the extract supplemented group at both concentrations. This reveals the capacity of the extract to prevent glycogen depletion on chronic ethanol administration (Fig. 3a and c).

\section{DNA content}

DNA material reacts with Schiff's reagent to form violet to pink colored nucleus. The study showed that the nuclei of cells in the cortex and medulla had dark pink-/violet-stained nucleus in control and only extrac-treated groups after Feulgen reaction. However, sections from the ethanol-treated group showed light pink-stained nucleus in renal and cortical cells, which may be due to damaged and disintegrated nucleic acid material due to the genotoxic effect of ethanol and its metabolites. $40.35 \%$ decreased DNA content in ethanol-treated group suggests increased damage of chromatin, indicative of progressive cellular apoptosis (Fig. 3b and d).

\section{Collagen deposition}

Sirius red stains the collagen fibers red in fixed tissues. It was observed that renal tissue from ethanol-treated rats when stained with Picrosirius showed significant and detectable amount of collagen deposition in the glomerulus and in between adjacent renal tubules. $63.27 \%$ increased collagen deposition was observed in ethanol-treated group when compared to control. Increased collagen deposition was, however, diminished by $51.76 \%$ and $49.54 \%$ when supplemented with the two different concentrations of the extract ACE250 and ACE500, respectively. The extent of collagen fiber deposition was almost negligible when the rats were pre-treated with the extract of ACE. Similarly, no significant collagen deposition was found in the control and only extract-treated groups. This shows that the extract prevents the development of tissue fibrosis by inhibiting collagen deposition (Fig. 4a-c).

\section{TUNEL assay}

To further confirm whether ethanol-induced renal injury was associated with apoptotic cell death, in situ TUNEL assay was carried out. Cells stained brown under light microscope and fluorescent green dots under 


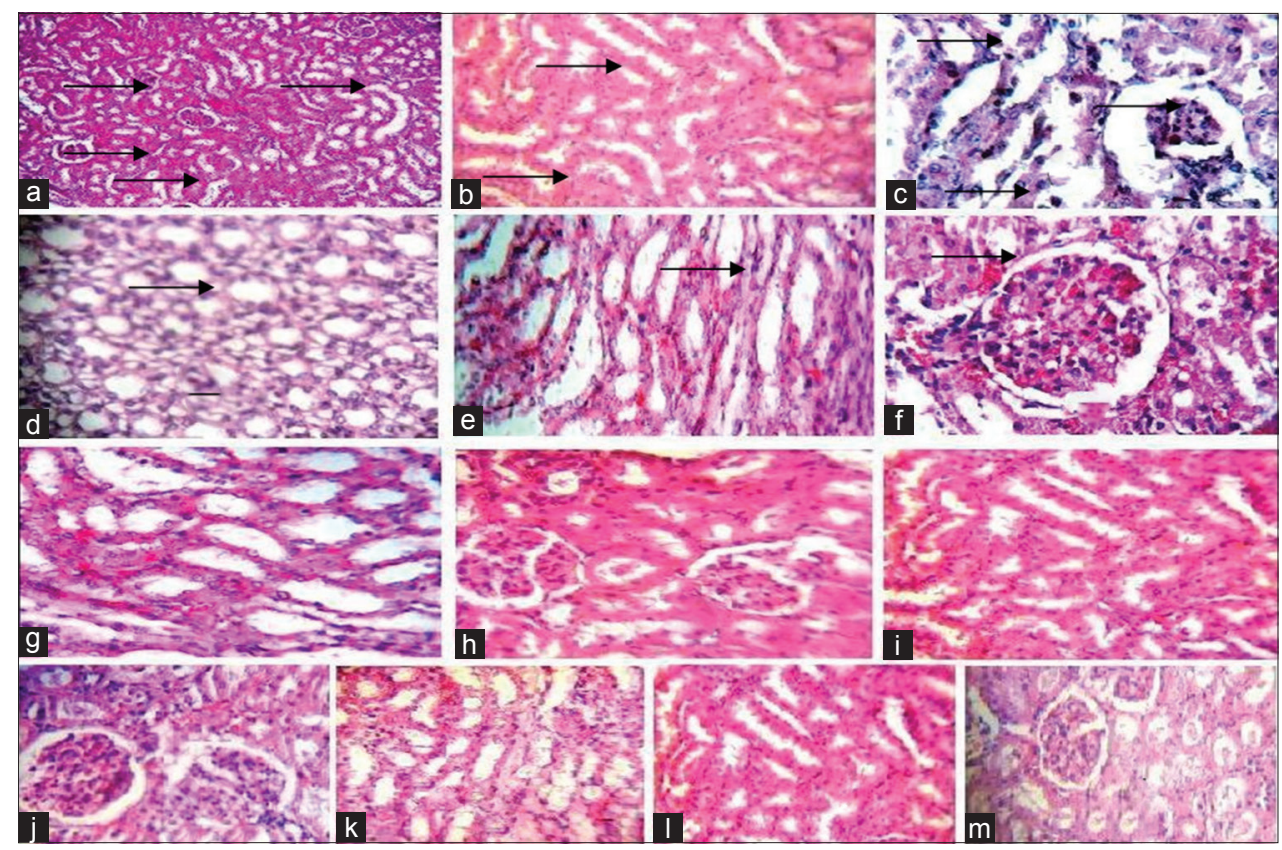

Fig. 2: Hematoxylin and Eosin stained sections from different experimental animal groups. (a and b) Kidney section from control group showing normal architecture. Black arrows indicate normal glomeruli and renal tubules, (c-e) kidney section from EtOH group with black arrows indicating damaged glomeruli, vacuolated cytoplasm, and dilated renal tubules, respectively, (f and g) kidney section from EtOH+ACE250 showing moderate protection of renal tissue with arrows indicating healthy glomerular basement membrane and less dilated renal tubules, (h and i) kidney section from EtOH+ACE500 showing almost normal architecture with the absence of tubular dilation and renal necrosis, (j-m) kidney sections from ACE250 and ACE500, respectively, showing normal architecture like that of the control group

confocal microscope are indicative of TUNEL-positive, apoptotic cells. In control and only extract-treated groups, very few positive cells were found. In contrast, the ethanol-treated group showed a greater number of positive cells in renal tubules. However, the number of positive cells declined on treatment with the extract at two different concentrations before ethanol administration. This indicates an antiapoptotic effect of the extract of ACE on renal tissue against ethanol-induced stress (Fig. 5). TUNEL assessed DNA fragment $/ \mathrm{mm}^{2}$ is significantly higher $(\mathrm{p}<0.001)$ in ethanol-treated group compared to control, while extract treatment markedly reduced $(\mathrm{p}<0.001)$ such fragmented DNA $/ \mathrm{mm}^{2}$.

\section{DISCUSSION}

Alcohol consumption and health outcomes are complex and multidimensional. As all the animals are maintained in the same condition and same room without showing any infection, the observed changes in biochemical and immunological parameters are due to ethanol and/or extract administration. It is well known that chronic alcohol consumption demonstrates a significant increase in free radical production and decrease in antioxidant status in the kidney of rats $[6,32]$. ROS accumulates in renal cortex and causes renal damage [33]. As a major finding of the present study, we demonstrated that alcohol-induced detrimental effects in renal cells are recovered with the administration of ethanolic extract of A. campanulatus. Ethanolinduced renal damage is manifested preliminarily by elevated levels of serum urea and creatinine along with increased BUN concentration. However, such elevation in urea, creatinine, and BUN level is prevented when the rats are given the ethanolic extract of ACE before ethanol showing the protective nature of the extract against ethanolic renal damage.

The current study also reveals a significant elevation in the serum TNF- $\alpha$ and IL-6 levels in ethanol-treated rats compared to normal control rats. The importance of immune system involvement in response to druginduced renal and hepatotoxicity has been well recognized over the past years. Ethanol-induced damage is associated with oxidative stress and immunological alterations [34]. It alters the levels of pro-inflammatory cytokines which play a critical role in cellular communication, activation, inflammation, cell death, and cell proliferation [35]. There exists a strict relationship between TNF- $\alpha$ and IL- 6 , which activates the innate and adaptive immune responses [36-38]. The mechanism by which ethanol exerts its modulatory effect on immune cells is not well understood. It has been suggested that alteration in membrane fluidity [39], protein phosphorylation, or protein-protein interactions ultimately result in change of signal transduction within the cell $[40,41]$. Literature data give evidence that ethanol-induced oxidative stress may be involved in the stimulation of cytokine production $[42,43]$. Many reports are consistent with the hypothesis that ethanol-induced ROS not only act as toxic substances but also stimulate signal transduction by activating redox-sensitive nuclear transcription factor (NF- $\mathrm{kB}$ ), which in turn leads to TNF- $\alpha$ production $[44,45]$. Moreover, it is also revealed that alcoholics and chronic ethanol-treated rats show an elevated level of serum IL-6, and it is suggested that this elevated IL-6 level is an adopted protective mechanism of the body in preventing apoptosis induced by ethanol [46]. The results of our study reveal the same and are in accordance with the findings from other authors [47]. Extract treatment shows prevention in the elevation of TNF- $\alpha$ and IL-6 levels unlike that of ethanol. The probable suggested mechanism can be attributed to the anti-inflammatory effect of the extract or the ability of the extract to prevent ROS generation, thereby inhibiting NF- $\mathrm{KB}$ stimulated cytokine production.

For kidneys, the pro-inflammatory cytokine TNF- $\alpha$ is the main orchestrator of the inflammatory response [48]. Histopathological observation of renal tissue sections from ethanol toxicant confirmed the biochemical data and showed clear signs of nephrotoxicity. H\&E stained sections reveal marked glomerular and tubular degeneration, ruptured glomerular basement membrane, inflammatory cell infiltration, vacuolization of tubular cells, and tubular dilation. Not only so, the renal cells show marked reduction in glycogen content and DNA amount as evident from PAS and Feulgen reaction, respectively. Glycogen depletion in chronic ethanol treatment may be due to 


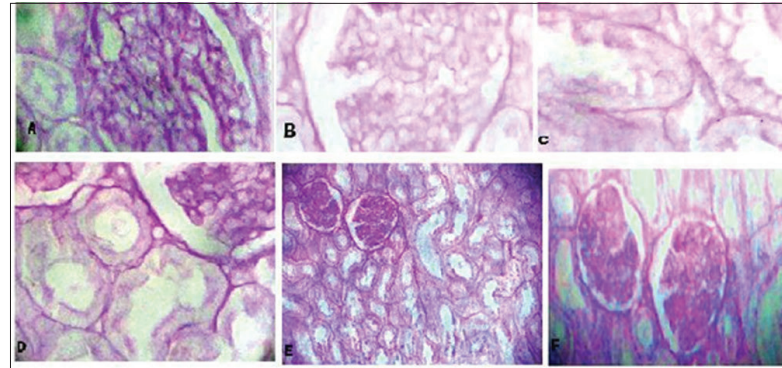

a
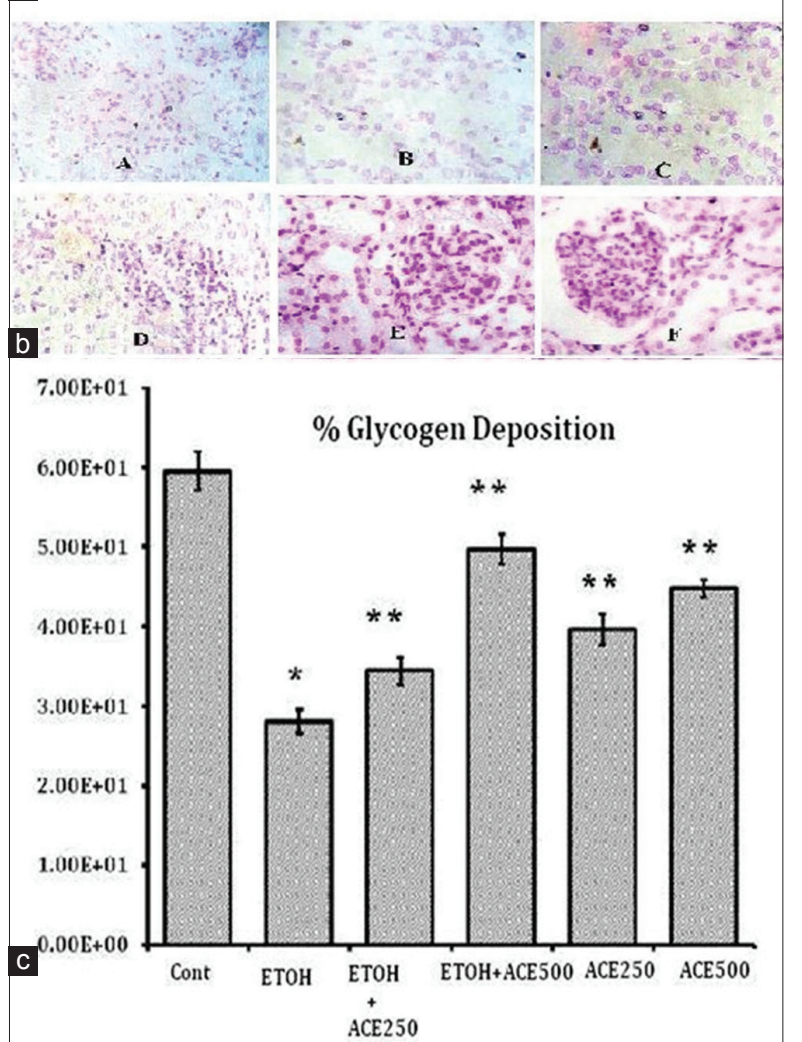

\% Area of DNA Content

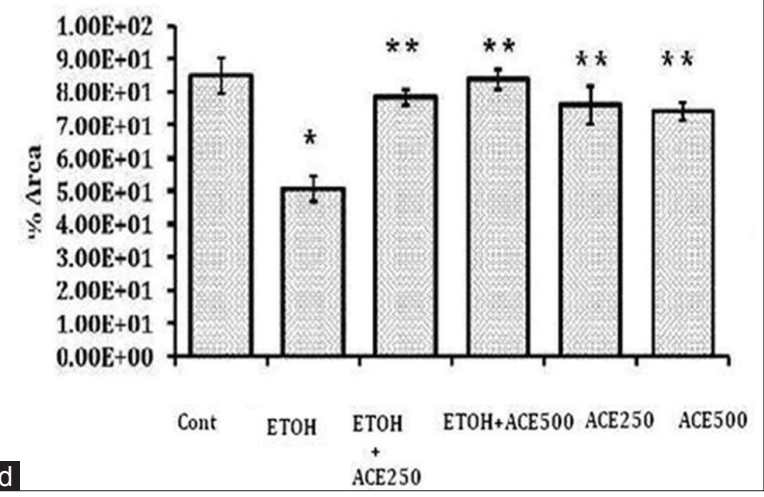

Fig. 3: Periodic acid schiff (a) and feulgen stained sections (b) from different experimental animal groups and corresponding $\%$ area of glycogen content (c) and DNA content (d). A - kidney section from control group showing normal glycogen content, B - kidney section from EtOH group showing marked reduction in glycogen content, C and D - kidney section from EtOH+ACE250 and EtOH+ACE500, respectively, showing restoration of glycogen content near normal, E and F - kidney section from ACE250 and ACE500, respectively, showing a normal amount of glycogen, all values are expressed as mean $\pm S D$, of 6 animals in each group. Data are analyzed by one-way analysis of variance followed by Tukey's-Kramer post hoc analysis. ${ }^{*} \mathrm{p}<0.001$ versus control, ${ }^{* *} \mathrm{p}<0.001$ versus only ethanol alteration of enzyme activity of glycolytic pathway, TCA cycle, and gluconeogenesis [49]. Some investigators also suggest that glycogen depletion is due to increased stress on the organ [50]. Low and fragmented DNA is an early marker of apoptosis, which is evidenced from Feulgen reaction. Overproduction of ROS in chronic ethanol treatment may be a leading cause for oxidative damage of biomolecules and DNA fragmentation [51]. Further confirmation of apoptosis was done by terminal deoxynucleotidyl transferase-mediated dUTP nick end labeling (TUNEL) reaction. Increased amount of terminal DNA labeling is observed in ethanol-treated rats indicating increased apoptosis induced by the said xenobiotics. Apoptosis can be initiated by many signaling pathways, including stimulation of death receptors (DRs), such as tumor necrosis factor receptor, by its respective ligand. In this study, we found that expression of TNF- $\alpha$ in the kidney is significantly increased in ethanol-treated rats in comparison to control rats. In the kidney, TNF- $\alpha$ can be synthesized by both intrinsic renal cells and infiltrating leukocytes [48]. Tubular cells become sensitized to apoptotic signals on exposure to inflammatory cytokines, such as TNF- $\alpha$ [52]. Thus, we hypothesize that the DR-mediated pathway plays a major role in apoptosis of renal tubular cells induced by ethanol. Abnormal apoptosis can result in a disruption of tissue homeostasis and function and is associated with many diseases [53], including numerous renal diseases in which the severity of renal injury is below the threshold for the development of necrosis [54]. Besides, an increased amount of collagen deposition is also observed among ethanol-treated animals, indicating the development of tissue fibrosis along extracellular matrix protein deposition with chronic ethanol administration. It is worth mentioning that renal morphology, glycogen storage capacity, extent of apoptosis, and collagen deposition in the extract administered group before ethanol are comparable with the normal control rats. Thus, the extract preserves the normal histochemical features even in the presence of continuous ethanol challenge.

Oxidative stress has been proposed to contribute to nephrotoxicity, and it has been suggested that ROS is the central key in the mechanism that leads to renal damage. According to our result, in the ethanol-treated group, the levels of endogenous antioxidants both enzymatic and nonenzymatic such as GSH, Cu-Zn SOD, Mn-SOD, and CAT are significantly lowered compared to the normal control rats. Glutathione (GSH) is a major non-protein thiol in living organisms, and it plays a central role in coordinating the body's antioxidant defense processes. It is critical in preserving the proper cellular redox balance and for its role as a cellular protectant. Antioxidant enzymes are key components of the cellular defense mechanisms to battle against oxidative stress [55]. SOD, the first and preliminary enzyme of the antioxidant defense system is involved in scavenging superoxide anion generated in response to redox balance disruption in chronic ethanol treatment [2]. It is a ubiquitous chain-breaking antioxidant and plays an important role in protection against deleterious effects of lipid peroxidation. The enzyme exists in three isoforms: Mn-SOD in mitochondria, $\mathrm{Cu} / \mathrm{Zn}-\mathrm{SOD}$ in cytosol, and extracellular-SOD in intercellular space. Not only so but also catalase plays a vital role in decomposition of hydrogen peroxide to water and oxygen, thus protecting the cellular components from oxidative damage by hydrogen peroxide [56]. It plays an important role in the acquisition of tolerance to oxidative stress in adaptive response of cells [57]. Decrease in Cu-SOD, Mn-SOD, and CAT activity with ethanol administration may cause accumulation of toxic free radicals which results in oxygen intolerance and triggers a number of deleterious reactions in vivo. However, it is observed that extract of ACE can prevent GSH depletion and enzyme exhaustion seen in ethanolic rats, thereby maintaining an elevated levels of GSH, Cu/Zn-SOD, Mn-SOD, and CAT like that of normal control rats. This protective effect of the extract may be attributed to its free radical scavenging property and the presence of antioxidant bioactive components in the extract.

Long-term alcohol exposure increases enzyme activities related to the recycling and utilization of glutathione in the kidney. In the current study, increased activity of GPx and GST in the ethanol-treated group may be correlated with the observed decrease in GSH content in response to chronic ethanol administration. The increased GSH participation in 


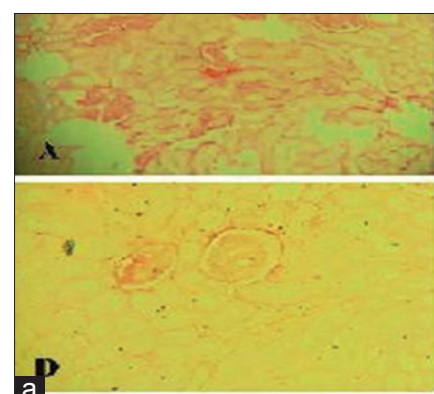

$a^{\mathbf{P}}$
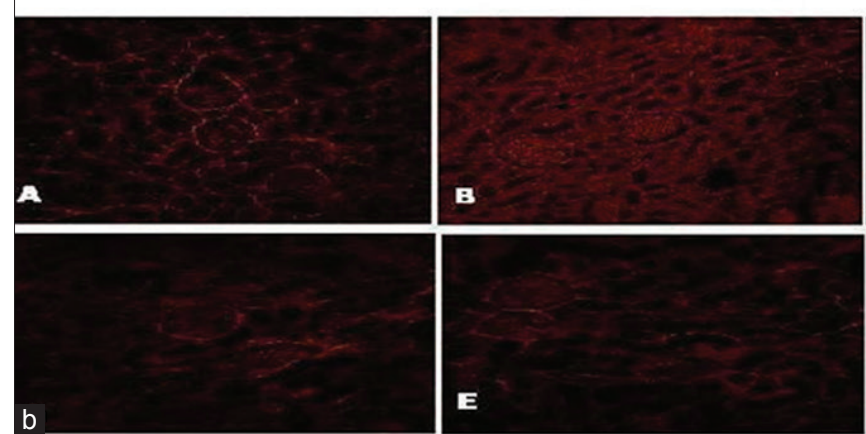

b
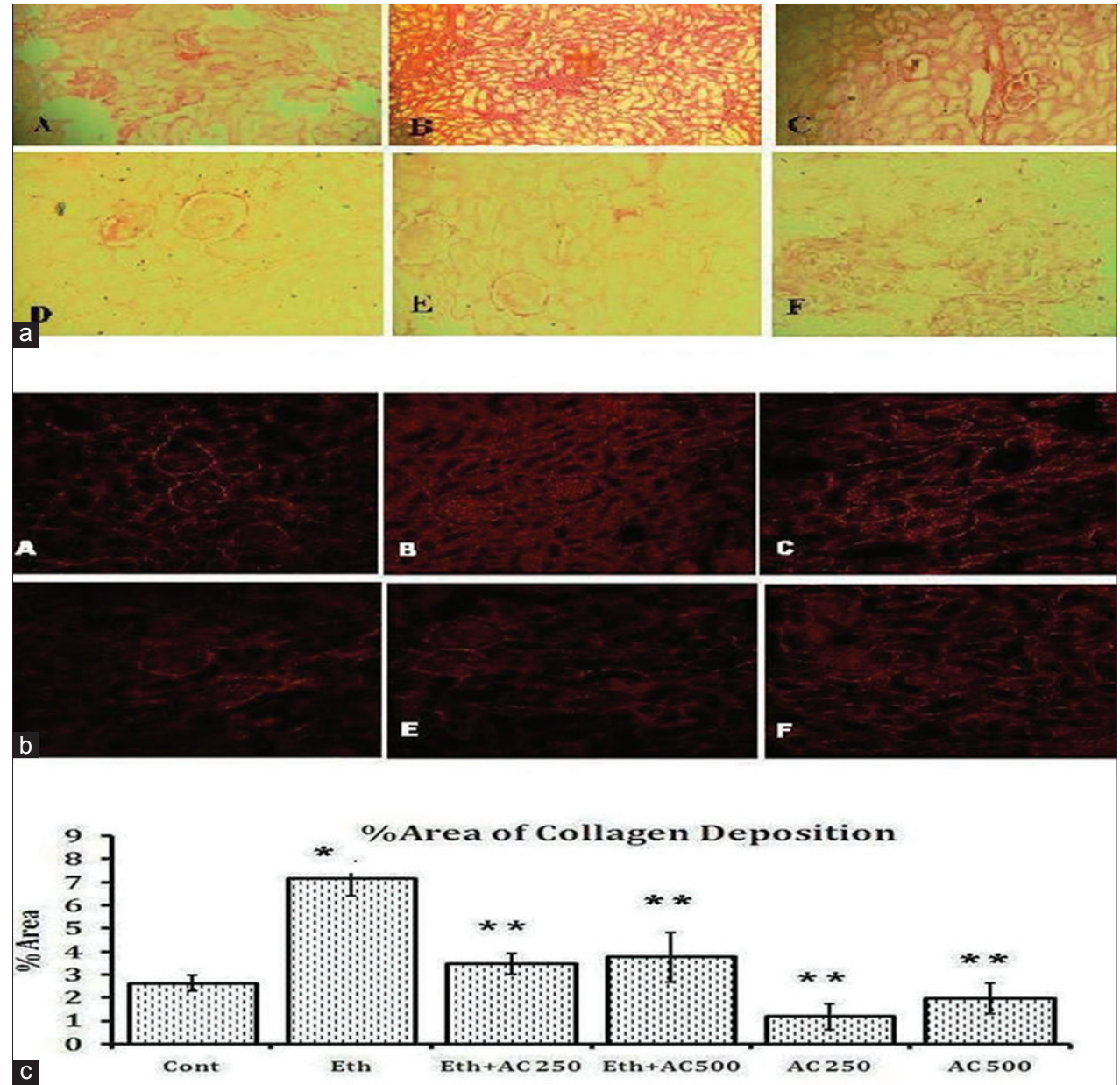

Fig. 4: Picrosirius stained sections under light (a) and confocal microscope (b) from different experimental animal groups with corresponding \% collagen deposition (c). A - Kidney section from control group showing negligible collagen content, B - kidney section from EtOH group showing a marked increase in collagen content, $C$ and $D$ - kidney section from EtOH+ACE250 and EtOH+ACE500, respectively, showing decreased collagen content near normal, E and F - Kidney section from ACE250 and ACE500, respectively, shows negligible collagen content like control. All values are expressed as mean $\pm S D$, of 6 animals in each group. Data are analyzed by one-way analysis of variance (ANOVA) followed by Tukey's-Kramer post hoc analysis. ${ }^{*}$ p $<0.001$ versus control, ${ }^{* *}$ p $<0.001$ versus only ethanol

S-conjugation reaction mediated by increased GST activity and as a cofactor in GPx-mediated reduction of peroxides seems to be a plausible model for the reduced GSH level in chronic ethanol administration [6]. When levels of primary antioxidant enzymes such as SOD and CAT decrease, the glutathione-dependent enzymes become activated. As stated above, in our study, we have seen that chronic ethanol treatment reduced the activities of both SOD and CAT in renal tissue. Hence, the increased activity of glutathione-dependent enzymes in renal tissue can be a possible second line of defensive strategy adopted by the body to protect its cellular components from oxidative stress. GPx, such as catalase, acts on hydrogen peroxide and lipid hydroperoxides, reducing the former to water and corresponding stable alcohol using glutathione as the reducing agent.

Striking changes concerning the enzymatic antioxidant response to ethanol-linked oxidative stress are recorded in the activities of GR and G6PD. The GR activity shows a substantial increase after ethanol consumption. This response is likely to be triggered by the relatively high GSSG levels in the kidney and probably plays an important role in preventing the deterioration of the GSH status after ethanol administration. Increased levels of GSSG also activate G6PD, the enzyme that provides the reducing power of NADPH, which is the cosubstrate required for GR activity in the recycling of GSSG [58]. Nevertheless, these enzymatic adaptations were insufficient to prevent the kidney GSH/GSSG ratio from a significant reduction that suggested an oxidative stress condition. The changes in the activity of these enzymes may be a protective response to peroxides generated under ethanol-induced redox imbalance. However, it is noted that the extract of ACE is effective in combating the changes in glutathione-related enzyme activity in the kidney. It is observed that ACE administration before ethanol prevented elevation of the activities of GST, GPx, GR, and G6PD by itself scavenging the peroxides generated and sparing the involvement of these enzymes in neutralizing the free radicals generated in response to ethanol challenge. Such change in the activities of the glutathione metabolizing enzymes observed in the current study is in accordance with that of Dinu et al., 2005.

Lipid peroxidation is a complex process that damages the cell structure and function. Peroxidation of membrane lipids initiates the loss of membrane integrity, membrane-bound enzyme activity, and cell lysis [59]. MDA, a marker of lipid peroxidation is significantly elevated with ethanol intoxication in the kidney tissue. It is well known that chronic ethanol ingestion elevates the MDA levels, which reflect extensive lipid peroxidation process in the liver, heart, and kidney of rats $[60,61]$. Unstable ROS that is generated during ethanol metabolism can react with membrane lipids and cause lipid peroxidation [62,63]. In the present study, a significant reduction in TBARS in groups receiving ACE as a supplement along with ethanol for 30 days is observed. This result suggests that ACE extract can protect the renal cells from ethanolinduced peroxidative damage. 


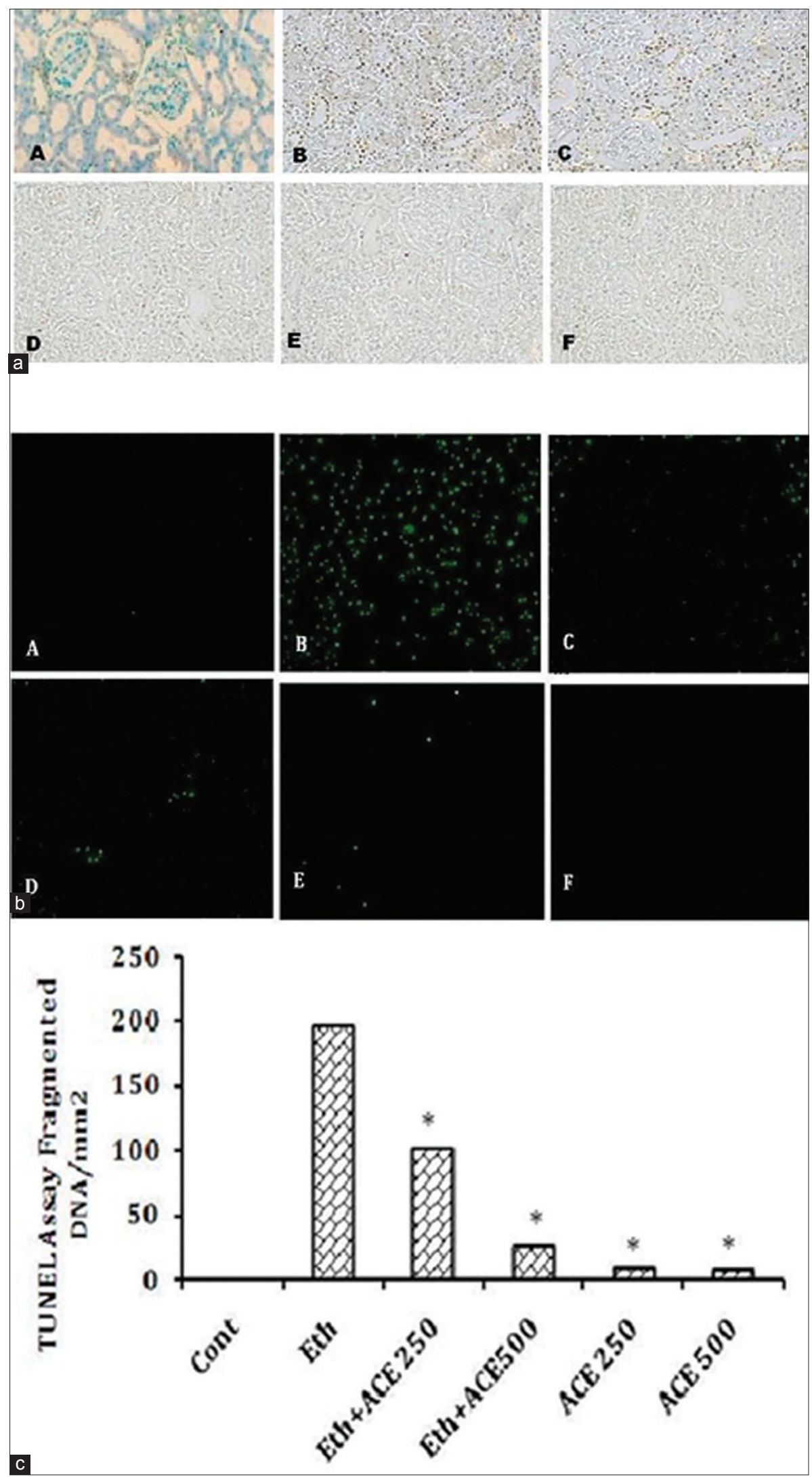

Fig. 5: TUNEL assay sections under (a) light, (b) confocal, and (c) fragmented DNA/ $\mathrm{mm}^{2}$ from different experimental animal groups. A - Kidney section from control group showing no DNA fragmentation, B - kidney section from EtOH group showing a marked increase in DNA fragmentation, C and D - kidney section from EtOH+ACE250 and EtOH+ACE500, respectively, showing decreased DNA fragmentation near to normal, E and F - kidney section from ACE250 and ACE500, respectively, shows negligible DNA fragmentation like control 


\section{CONCLUSION}

The results confirmed that ethanol-induced renal toxic effect may be due to free radical mechanism. Extensive free radical generation due to ethanol and its metabolites disrupt the cellular antioxidant defense, thereby generating an environment favorable for oxidative stress. Free radicals are thought to alter the levels of enzymatic and nonenzymatic endogenous antioxidants in vivo and also simultaneously activate transcription factors responsible for production of proinflammatory cytokines. These cytokines in turn can activate cellular apoptotic machinery leading to apoptosis of cells. However, it is observed that, due to the ability of the extract to scavenge free radicals, the cellular antioxidant defense is not disrupted, and inflammatory and apoptotic pathways are not triggered. Reno-protective effect of the extract on concurrent administration with ethanol is specifically attributed to the identified components in the extract that might contribute to its antioxidative, antiapoptotic, and anti-inflammatory property. Alternative medicine in the management of disease is gaining importance and emerging as an extensive field of research for the drug development industry. Therefore, further study at molecular level exploring the transcription and translation of genes due to ethanol to generate the deleterious effects and simultaneous inhibition of such pathways to combat the challenge by the extract is essential for future therapeutic intervention and drug development.

\section{ACKNOWLEDGMENT}

The first author gratefully acknowledges the receipt of a Senior Research Fellowship (SRF) under INSPIRE program of Department of Science and Technology, Government of India. The University Grants Commission [F. No. 42-625/2013(SR)] is also acknowledged for financial grant. The authors also acknowledge Dr. Pranabes Nath and Dr. Samarendra Nath Banerjee, faculty Rammohan College, for their constant cooperation and guidance throughout the study. Special gratitude is expressed to Sri Sumanto Ghosal for Technical assistance.

\section{REFERENCES}

1. Adaramoye OA, Aluko A. Methanolic extract of Cnidoscolus aconitifolius attenuates renal dysfunction induced by chronic ethanol administration in Wistar rats. Alcohol Alcohol 2011;46:4-9.

2. Shanmugam KR, Ramakrishna $\mathrm{CH}$, Mallikarjuna $\mathrm{K}$, Reddy $\mathrm{KS}$. Protective effect of ginger against alcohol-induced renal damage and antioxidant enzymes in male albino rats. Indian J Exp Biol 2010;48:143-9.

3. Husain K, Scott BR, Reddy SK, Somani SM. Chronic ethanol and nicotine interaction on rat tissue antioxidant defense system. Alcohol 2001;25:89-97.

4. Clemens DL, Jerrells TR. Ethanol consumption potentiates viral pancreatitis and may inhibit pancreas regeneration: Preliminary findings. Alcohol 2004;33:183-9.

5. Baskaran M, Periyasamy L, Rajagopalan R. Effect of Phyllanthus niruri on alcohol and polyunsaturated fatty acid induced oxidative stress in liver. Int J Pharm Pharm Sci 2010;2 Suppl 4:58-62.

6. Dinu D, Nechifor MT, Movileanu L. Ethanol-induced alterations of the antioxidant defense system in rat kidney. J Biochem Mol Toxicol 2005; 19:386-95.

7. Ndhlala AR, Moyo M, Van Staden J. Natural antioxidants: Fascinating or mythical biomolecules? Molecules 2010;15:6905-30.

8. Palaniswamy R, Raghunathan PP. Protective effect of Bacopa monnieri leaf extract against oxidative stress hepatotoxicity in rats. Int J Pharm Pharm Sci 2013;5 Suppl 3:555-8

9. Basu S, Das M, Datta G. Phytochemical evaluation and study of in vitro antioxidant potential of ethanolic and aqueous extracts of Amorphophallus campanulatus: A popular tuber of West Bengal. Int J Res Pharm Sci 2012;3:287-95.

10. Basu S, Choudhury UR, Das M, Datta G. Identification of bioactive components in ethanolic and aqueous extracts of Amorphophallus campanulatus tuber by GC-MS analysis. Int J Phytomed 2013;5:243-51.

11. Basu S, Das M, Datta G. Protective activity of ethanolic extract of Amorphophallus campanulatus against ethanol induced hepatotoxicity in rats. Int J Pharm Pharm Sci 2013;5:412-7.

12. OECD. Guideline for Testing of Chemicals, Guidance No. 423, Acute Oral Toxicity: Acute Toxic Class Method. Paris: OECD; 2001.
13. Lorke UC. Determination of lethal dose of xenobiotics in experimental animals. Nature 1983;45:264-6.

14. Iwaniec UT, Turner RT. Intraperitoneal injection of ethanol results in drastic changes in bone metabolism not observed when ethanol is administered by oral gavage. Alcohol Clin Exp Res 2013;37:1271-7.

15. Collier SD, Wu WJ, Pruett SB. Ethanol suppresses NK cell activation by polyinosinic-polycytidylic acid (poly I: C) in female B6C3F1 mice: Role of endogenous corticosterone. Alcohol Clin Exp Res 2000;24:291-9.

16. D'Souza El-Guindy NB, de Villiers WJ, Doherty DE. Acute alcohol intake impairs lung inflammation by changing pro- and antiinflammatory mediator balance. Alcohol 2007;41:335-45.

17. Mitra A, Ray A, Datta R, Sengupta S, Sarkar S. Cardioprotective role of P38 MAPK during myocardial infarction via parallel activation of a-crystallin B and Nrf2. J Cell Physiol 2014;229:1272-82.

18. Marsh WH, Fingerhut B, Miller H. Automated and manual direct methods for the determination of blood urea. Clin Chem 1965;11:624-7.

19. Vasiliades J. Reaction of alkaline sodium picrate with creatinine: I. Kinetics and mechanism of formation of the mono-creatinine picric acid complex. Clin Chem 1976;22:1664-71.

20. Zheleva A, Tolekova A, Zhelev M, Dobreva Z, Halacheva K, Popova S. In vivo antioxidant and prooxidant properties of Amanita phalloides mushroom toxins. Trakia J Sci 2005;3:34-8

21. Marklund S, Marklund G. Involvement of the superoxide anion radical in the autoxidation of pyrogallol and a convenient assay for superoxide dismutase. Eur J Biochem 1974;47:469-74.

22. Aebi H. Catalase in vitro. Methods Enzymol 1984;105:121-6.

23. Ellman GL. Tissue sulfhydryl groups. Arch Biochem Biophys 1959;82:70-7

24. Ohkawa H, Ohishi N, Yagi K. Assay for lipid peroxides in animal tissues by thiobarbituric acid reaction. Anal Biochem 1979;95:351-8.

25. Rotruck JD. Selenium: Biochemical role as a component of glutathione peroxidase and assay. Science 1973;179:588-90.

26. Racker E. Glutathione reductase (liver and yeast). In: Colowick SP, Kaplan NO, editors. Methods in Enzymology. Vol. 2. New York: Academic Press; 1955. p. 722-5.

27. Habig WH, Pabst MJ, Jakoby WB. Glutathione S-transferases. The first enzymatic step in mercapturic acid formation. J Biol Chem 1974;249:7130-9.

28. Lee CY. Glucose-6-phosphate dehydrogenase from mouse. Methods Enzymol 1982;89:252-7.

29. Lowry OH, Rosebrough NJ, Farr AL, Randall RJ. Protein measurement with the folin phenol reagent. J Biol Chem 1951;193:265-75.

30. Banchroft JD, Stevens A, Turner DR, editors. Theory and Practice of Histological Techniques. New York, London, San Francisco, Tokyo: Churchil Livingstone; 1996.

31. Rich L, Whittaker P. Collagen and picrosirius red staining: A polarized light assessment of fibrillar hue and spatial distribution. Braz J Morphol Sci 2005;22:97-104.

32. Galazyn-Sidorczuk M, Brzóska MM, Jurczuk M, Moniuszko-Jakoniuk J. Oxidative damage to proteins and DNA in rats exposed to cadmium and/or ethanol. Chem Biol Interact 2009;180:31-8.

33. Geetha K, Ramarao N, Sindhu B, Rao VU. Nephroprotective, nephrocurative activity of Mimosa pudica root against gentamicin induced nephrotoxicity. Int J Pharm Pharm Sci 2015;7:173-7.

34. Das SK, Gupta G, Rao DN, Vasudevan DM. Effect of lecithin with Vitamin-B complex and tocopheryl acetate on long-term effect of ethanol induced immunomodulatory activities. Indian J Exp Biol 2007;45:683-8.

35. Crews FT, Bechara R, Brown LA, Guidot DM, Mandrekar P, Oak S, et al. Cytokines and alcohol. Alcohol Clin Exp Res 2006;30:720-30.

36. Banno T, Gazel A, Blumenberg M. Effects of tumor necrosis factoralpha (TNF alpha) in epidermal keratinocytes revealed using global transcriptional profiling. J Biol Chem 2004;279:32633-42.

37. Billiau A. Interferon-gamma: Biology and role in pathogenesis. Adv Immunol 1996;62:61-130.

38. Arrend WP. The balance between IL-1 and IL-1R in disease. Cytokine Growth Factor Rev 2002;13:323-40.

39. Goldstein DB. Ethanol-induced adaptation in biological membranes. Ann N Y Acad Sci 1987;492:103-11.

40. Hoek JB, Rubin E. Alcohol and membrane-associated signal transduction. Alcohol Alcohol 1990;25:143-56.

41. Zeldin G, Yang SQ, Yin M, Lin HZ, Rai R, Diehl AM. Alcohol and cytokine-inducible transcription factors. Alcohol Clin Exp Res 1996;20:1639-45.

42. Zhou Z, Wang L, Song Z, Lambert JC, McClain CJ, Kang YJ. A critical involvement of oxidative stress in acute alcohol-induced 
hepatic TNF-alpha production. Am J Pathol 2003;163:1137-46.

43. McClain CJ, Song Z, Barve SS, Hill DB, Deaciuc I. Recent advances in alcoholic liver disease. IV. Dysregulated cytokine metabolism in alcoholic liver disease. Am J Physiol Gastrointest Liver Physiol 2004;287:G497-502.

44. Wheeler MD, Yamashina S, Froh M, Rusyn I, Thurman RG. Adenoviral gene delivery can inactive Kupffer cells: Role of oxidants in NF- $\mathrm{KB}$ activation and cytokine production. J Leukoc Biol 2001;69:622-30.

45. Yin M, Gäbele E, Wheeler MD, Connor H, Bradford BU, Dikalova A, et al. Alcohol-induced free radicals in mice: Direct toxicants or signaling molecules? Hepatology 2001;34:935-42.

46. El-Assal O, Hong F, Kim WH, Radaeva S, Gao B. IL-6-deficient mice are susceptible to ethanol-induced hepatic steatosis: IL-6 protects against ethanol-induced oxidative stress and mitochondrial permeability transition in the liver. Cell Mol Immunol 2004;1:205-11.

47. Moniuszko-Jakanuik J, Jurczuk M, Galazyn-Sidorczuk M. Evaluation of some immunomodulatory cytokines in serum of rats exposed to cadmium and ethanol. Polish J Environ Stud 2009;18:673-80.

48. Ortiz A. Apoptotic regulatory proteins in renal injury. Kidney Int 2000;58:467-85

49. Shakoori AR, Ali SS, Saleem MA. Effects of six months' feeding of cypermethrin on the blood and liver of albino rats. J Biochem Toxicol 1988;3:59-71.

50. Ebaid H, Dkhil MA, Danfour MA, Tohamy A, Gabry MS. Piroxicaminduced hepatic and renal histopathological changes in mice. Libyan $\mathrm{J}$ Med 2007;2:82-9.

51. Halliwell B, Gutteridge JM. Role of free radicals and catalytic metal ions in human disease: An overview. Methods Enzymol 1990;186:1-85.

52. Lorz C, Benito-Martín A, Boucherot A, Ucero AC, Rastaldi MP, Henger A, et al. Pro-apoptotic fas ligand is expressed by normal kidney tubular epithelium and injured glomeruli. J Am Soc Nephrol
2000;11:1266-77

53. Fadeel B, Orrenius S, Zhivotovsky B. Apoptosis in human disease: A new skin for the old ceremony? Biochem Biophys Res Commun 1999;266:699-717.

54. Ueda N, Baliga R, Shah SV. Role of 'catalytic' iron in an animal model of minimal change nephrotic syndrome. Kidney Int 1996;49:370-3.

55. Wen YF, Zhao JQ, Bhadauria M, Nirala SK. Baicalin prevents cadmium induced hepatic cytotoxicity, oxidative stress and histomorphometric alterations. Exp Toxicol Pathol 2013;65:189-96.

56. Saravanan R, Rajendra Prasad N, Pugalendi KV. Effect of Piper betle leaf extract on alcoholic toxicity in the rat brain. J Med Food 2003;6:261-5

57. Sankaran M, Vadivel A, Thangam A. Curative effect of garlic on alcoholic liver diseased patients. Jordan J Biol Sci 2010;3:147-52.

58. Reed DJ. Regulation of reductive processes by glutathione. Biochem Pharmacol 1986;35:7-13.

59. Romero FJ, Bosch-Morell F, Romero MJ, Jareño EJ, Romero B, Marín N, et al. Lipid peroxidation products and antioxidants in human disease. Environ Health Perspect 1998;106 Suppl 5:1229-34.

60. Mallikarjuna K, Sahitya Chetan P, Sathyavelu Reddy K, Rajendra W. Ethanol toxicity: Rehabilitation of hepatic antioxidant defense system with dietary ginger. Fitoterapia 2008;79:174-8.

61. Bindu MP, Sreekant KS, Annamali PT, Augusti KT. Effect of S-allile cysteine sulophoxide on lipid metabolism and free radical scavenges in alcohol fed rats. Curr Sci 2002;82:628-31.

62. Mallikarjuna K, Nishanth K, Hou CW, Kuo CH, Sathyavelu Reddy K. Effect of exercise training on ethanol-induced oxidative damage in aged rats. Alcohol 2009;43:59-64.

63. Das SK, Vasudevan DM. Effect of ethanol on liver antioxidant defense system: A dose dependent study. Indian J Clin Biochem 2005;20:80-4 